\title{
Uptake of Climate Smart Agriculture in Peri-Urban Areas of South Africa's Economic Hub Requires Up-Scaling
}

\section{Munyaradzi Chitakira* and Nombuso Z. P. Ngcobo}

Department of Environmental Science, School of Ecological and Human Sustainability, University of South Africa, Pretoria, South Africa

Climate variability and change impact significantly on food security and the livelihoods of smallholder farmers making it necessary for the farmers to prioritize investment in adaptation and mitigation approaches, such as climate smart agriculture, to enhance resilience. Climate smart agriculture approaches have been adopted in many countries around the world to address the adverse impacts of climate change on agricultural production. There is limited information about climate smart agriculture adoption by peri-urban farmers in developing countries. The present study aimed to assess the extent to which agricultural activities by smallholder crop farmers in the City of Tshwane Metropolitan Municipality in Gauteng province of South Africa are climate smart, and to establish the sustainable measures to be put in place to enhance the adoption of climate smart agriculture. The study made use of a mixed method design combining qualitative and quantitative approaches. A combination of simple random and non-probability sampling techniques was employed to select the study locations and identify respondents. A sample of thirty-six farmers were selected for the study. The main findings revealed overwhelming awareness of climate change and the impacts thereof on crop productivity and yields. However, the respondents' level of awareness of climate smart agriculture technologies was generally low. Despite the lack of knowledge of climate smart agriculture practices, the farmers were, to an extent, utilizing adaptation mechanisms acquired from indigenous systems or scientific knowledge. Examples of these practices include mulching, cover cropping, crop rotation and use of crop varieties. The study concludes that much more can be done to scale up the uptake of climate smart agriculture in the Gauteng province. The study recommends formal and informal strategies including one-on-one extension programs to raise the awareness of climate smart agriculture technologies appropriate to the unique conditions of the farmers.

Keywords: climate variability and change, climate smart farming practices, smallholder crop farmers, Gauteng province, food security

\section{INTRODUCTION}

Numerous scientific studies have confirmed that climate variability and change severely affect the environment, food production and food security, causing detrimental socioeconomic and livelihood impacts on smallholder farmers particularly in developing countries (Iizumi and Ramankutty, 2015; Elum et al., 2017). Climate change causes a disruption of traditional agricultural practices and the livelihoods of smallholder communities who practice semi-subsistence farming and earn a living through farming (Mathews et al., 2018). 
The term climate variability implies the "variations in the mean state and other statistics (such as standard deviations, the occurrence of extremes, etc.) of the climate on all spatial and temporal scales beyond that of individual weather events" (IPCC, 2018 , p.8). Variability may occur naturally due to processes within the climate system or may result from variations in natural or anthropogenic external forcing. On the other hand, climate change refers to a change in the state of the climate identifiable by changes in the mean or the variability of its properties and that keeps on for decades or longer (IPCC, 2018). Climate change is attributable to natural internal processes or external forces including anthropogenic. According to the UNFCCC (2013), climate change is attributable to human activities that alter the composition of the atmosphere while climate variability is attributable to natural causes.

The realities of climate variability and change call for drastic action by farmers to combat the potential detrimental impacts on food production and food security, the environment, as well as the resilience, sustainability and livelihoods. Potential and sustainable action include adaptation strategies which enable farmers to cope with socioeconomic, environmental and agricultural production challenges, such as implementing climate smart agriculture (CSA) (Barnard et al., 2015).

The concept of CSA emerged a decade ago, motivated by a need to develop solutions for the integrated goals of: (a) increasing agricultural productivity and yields, (b) reducing greenhouse gas (GHG) emissions from the agricultural sector, (c) enhancing resilience, and (d) increasing adaptation of farmers and agricultural systems ( Food Agricultural Organisation, 2010; Andrieu et al., 2017). CSA strategies and technologies have been in use in many countries around the world to address climate change issues and to improve economic growth and the growth of the agriculture sector (World Bank et al., 2014). Another concept which recently emerged, and which is often associated with CSA is climate resilient agriculture (CRA). Some authors tend to use these terms interchangeably (Viswanathan et al., 2020). However, CSA is a much broader term that encompasses CRA. It is noted that CRA includes agricultural practices and technologies which enhance resilience and increase the capacity of smallholder farming systems to withstand disturbances from climatic factors and enable quick recovery (Rao et al., 2019). In the context of the present study, the two terms largely overlap since the CSA practices under focus are more toward enhancing the resilience of smallholder farmers than achieving the other CSA goals.

The growing importance of urban and peri-urban agriculture in meeting human and ecological needs is evident in literature (Cofie et al., 2003; Moreau et al., 2012), and so is the urgency for taking measures to ensure the sustainability of these agricultural systems (Dube et al., 2021). In the wake of these observations, the current study seeks to investigate how climate-smart the smallholder agriculture in peri-urban areas of South Africa's Gauteng province is.

\section{STUDY AIM}

The aim of this study was to assess agricultural practices by periurban smallholder farmers in the Gauteng province of South
Africa in order to determine the extent to which the practices are climate smart. The study was intended to produce information which would guide recommendations for sustainable measures required to promote the uptake (or increased adoption) of climate smart farming practices in the study area and other areas with comparable conditions.

\section{STUDY RATIONALE}

Agriculture within and around cities is expanding and this makes it important to promote production systems that aim to achieve increased food security, reduced carbon emissions and enhanced resilience to climate change (Moreau et al., 2012). Urban and peri-urban agriculture has historically been making a significant contribution to food availability and healthy diets in many cities in southern Africa (Cofie et al., 2003). A great deal of research on smallholder agriculture in Africa has focused on the impact of climate change on agricultural production and on adaptation strategies used by the farmers. Information about the extent and the impact of CSA adoption in peri-urban areas on the continent and in South Africa in particular is still limited. On one hand, the global challenge of climate change and variability is putting urban and peri-urban agriculture under immense pressure. On the other hand, research shows that appropriate adaptation strategies can enhance the resilience and sustainability of these agricultural systems (Dube et al., 2021). The sustainability of peri-urban agriculture is important considering the critical role this production system plays. Apart from meeting the increasing demand for food in urban areas, urban and peri-urban agriculture provides employment and creates income for the farmers (Anaafo and Akolgo, 2018). It is well-documented that CSA has been implemented in many parts of the world (World Bank et al., 2014). It is of interest to find out at the local scale, the extent of adoption of these technologies and how they are possibly transforming smallholder agriculture.

The present study addresses an important and growing theme in the global context, and which focuses on action to address the United Nations Sustainable Development Goals (SDGs). By addressing challenges of food security and enhancing the resilience and sustainability of smallholder agricultural systems, CSA can address a couple of SDGs, either directly or indirectly. These include SDG 1 (No poverty), SDG 2 (Zero hunger), SDG 13 (Climate action), and SDG 15 (Life on land). The results from this case study are hoped to give insights on existing gaps and what options to take in order to improve the scale of CSA adoption by smallholder farmers in peri-urban environments. The relatively small sample used in this study may however limit the potential to generalize and apply the findings to other peri-urban areas elsewhere.

\section{REVIEW OF RELATED LITERATURE}

CSA comprises practices and technologies useful for adaptation to climate change by farmers and helps to increase productivity whilst simultaneously reducing GHG emissions. CSA may also assist governments in achieving national food security as well as reducing poverty (Barnard et al., 2015). CSA practices which are 
appropriate for enabling farmers to effectively adapt to climate change range from the use of techniques and mechanisms suited for farm-level operations to international policy and finance mechanisms. Examples of such technologies and techniques include agro-forestry, mulching, minimum tillage, crop rotation, water conservation, methane reducing rice systems and soil cover maintenance (Barnard et al., 2015).

It is noted that CSA is not a one-size-fits-all practice or one particular strategy, but an array of practices integrated into an agricultural system at various scales (Thierfelder et al., 2017). It is further noted that there is no CSA blueprint and that its implementation is subjected to a country or community's specific context (Food Agricultural Organisation, 2010). Nagargade et al. (2017) observe that CSA strategies incorporate traditional and innovative practices and technologies relevant to a location's context for the adaptation of climate change. Partey et al. (2018) point out that there are uncertainties around the practice with regard to what technologies and practices should be categorized as CSA and which of the three pillars (productivity, adaptation, and mitigation) should be given priority in any given context.

Lima (2014) identifies some technologies and practices generally used by some African countries. The Democratic Republic of Congo invested in irrigation management, droughttolerant seed variety production and information dissemination. Strategies implemented by Lesotho include conservation agriculture, soil organic matter management, agroforestry and production of drought-tolerant crops and cultivars. Malawi practices minimum tillage, agroforestry and utilizes herbicides. Mauritius practices a variety of technologies including mixedcropping, crop rotation, pest control based on indigenous knowledge systems, pit planting, adjustment of planting dates, and the use of rainwater harvesting ponds on the fields. There are a number of CSA practices that have been adopted in South Africa. These include no tillage, crop diversification, crop rotation, intercropping, mulching, management of pest, disease and weed and improved soil fertility (Blignaut et al., 2015; Schulze, 2016).

Despite the wide range of benefits that CSA practices offer to low income and vulnerable farming communities, the adoption of CSA remains a challenge in Africa. Less than 1 million hectares of farmland is under CSA and a greater part of this is implemented by commercial farms (Milder et al., 2011). The lag and lack of CSA in Africa is mostly due to several barriers that hinder adaptation by smallholder farmers. The barriers include a lack of financial resources, infrastructure, skills, or awareness of CSA technologies (Rakgase and Norris, 2015). A majority of smallholder and subsistent agricultural systems are rain-fed and have limited access to technological inputs (Pereira, 2017). Some regions have high population densities and experience land degradation. Such areas tend to lack crop residue and other forms of biomass (that could be utilized for mulching or soil fertility) due to its demand for other purposes such as livestock fodder fuel or construction (Barnard et al., 2015).

\section{Evidence of Changes in Weather and Climate Patterns}

Globally, the agricultural sector faces unprecedented changes relating to changes in weather and climate patterns with observable shifts in seasons and rainfall threatening crop yields and the availability of food. Over the past half century, South Africa's temperatures have shown an overall increasing trend although not as steady as the global change (Schulze, 2016) as seen in Figure 1.

There is evidence that the Gauteng province of South Africa has generally seen increases of mean maximum as well as minimum temperatures. As noted by the Gauteng Department of Agriculture Rural Development (2017) the province has shown trends of increased temperatures in the period 1931-2015 of more than $2^{\circ} \mathrm{C} /$ century, which proves to be much higher in comparison to the mean global warming trend in the last century of $\sim 1^{\circ} \mathrm{C}$. This is due to the rapid urbanization of the province leading to an increasing heat island effect (City of Tshwane, 2015).

Production of various types of field crops in South Africa has shown a steady shift in total crop area in response to climate variability. In particular, the crop area under white maize dropped from 1.5 million hectares to 1.1 million hectares (Department of Environmental Affairs, 2016). Further, the production of dryland wheat in the Free State, Limpopo and North West provinces has declined, from around one million hectares in the late 1990 s to 200000 hectares by 2013 . The Gauteng province experienced $57 \mathrm{~mm}$ less rainfall between 1985 and 2014 which implies a significant effect of climate variability. In addition, the province experienced temperature increases of about $0.5^{\circ} \mathrm{C}$ which potentially increased the occurrence of droughts (Elum et al., 2017). There was a decline in production of potatoes and cabbages as $77 \%$ of potato farmers and $67 \%$ of cabbage farmers across the provinces experienced challenges of high/extreme temperature (Elum et al., 2017). It is noted that these trends were experienced due to the lack of risk mitigation measures by the farmers thereby exposing the crops to climatic risks (Department of Environmental Affairs, 2016). This in turn exposed the production and socioeconomic vulnerabilities of farmers in South Africa, particularly of smallholder farmers.

\section{CSA as an Adaptation Option}

The Intergovernmental Panel on Climate Change (2007) defines adaptation as the moderation of harm of actual or expected climatic effects or pressures through adjusting natural or human systems. According to Akinnagbe and Irohibe (2014), adaptation involves employing appropriate steps and procedures or adopting necessary adjustments to reduce the effects of climate change. It also involves the exploitation of positive effects. The aim of adaptation is to reduce exposure to risk, improve one's capacity of coping to risks and damage, and to exploit new opportunities.

According to the Food Agricultural Organisation (2010) adaptation to climate change is vital for the achievement of food security and agricultural development goals. KhatriChhetri et al. (2017b) note that there are adaptation options that may be utilized to achieve the reduction of climatic risks in the agricultural sector. CSA services, technologies and practices are adaptation options used to increase productivity, enhance resilience to climate variability and to reduce GHG emissions (Khatri-Chhetri et al., 2017b). These options include practices such as minimum tillage, 


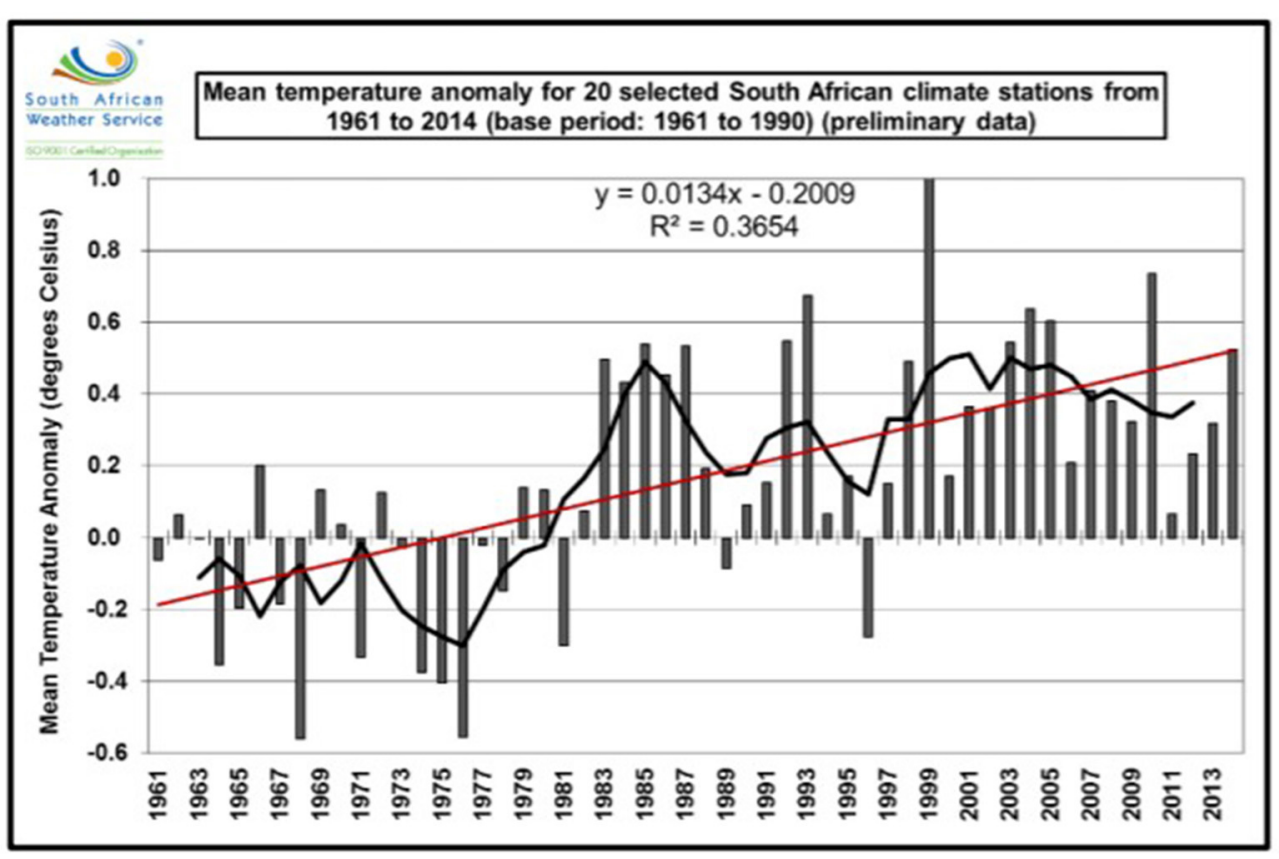

FIGURE 1 | Mean temperature anomaly for 20 South African climate stations from 1961 to 2014 (Source: South African Weather Services, 2015).

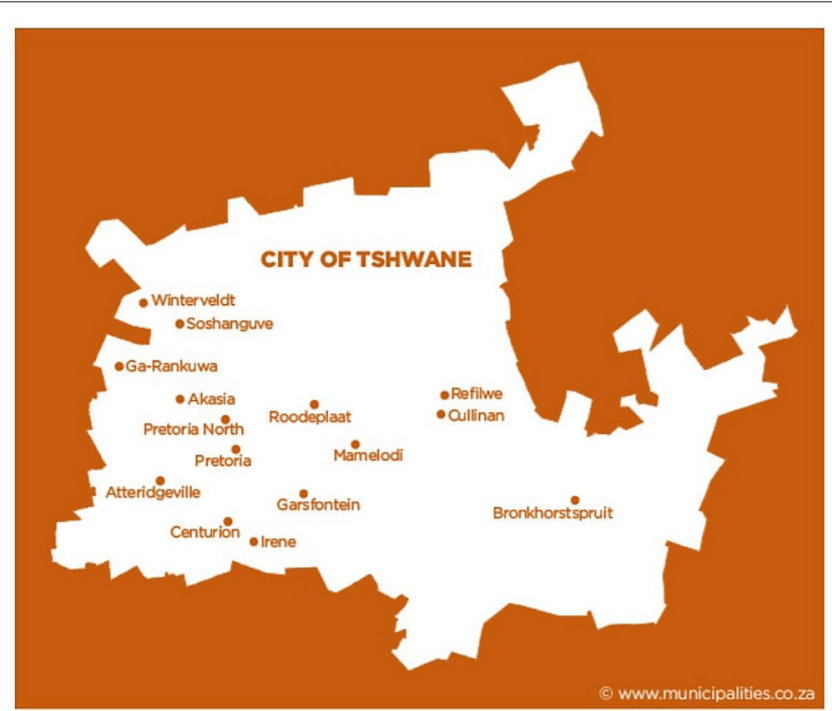

FIGURE 2 | Study locations in the City of Tshwane Metropolitan Municipality (Source: Government of South Africa, 2021).

various crop establishment methods, the management of nutrients and irrigation as well as water use efficiency and management.

A study by Finger and Schmid (2007) projected Research has shown that there are increased yields when a change in crop sowing dates combined with the use of irrigation technologies were applied. It also resulted in less variations when compared to the case where adaptation measures were not implemented. Similar cases of farm level studies indicated that crop yields, input use efficiency and net income increased with the adoption of CSA. An on-farm experimental study conducted by KhatriChhetri et al. (2017a) across South Asia revealed that the implementation of a single or a combination of technologies had a significant positive impact on rice and wheat yields. For instance, an increase of $83 \%$ and $23 \%$ of rice and wheat yield, respectively, was realized from the use of nutrient and water management technologies.

The preceding sections have shown that there is a variety of technologies and practices available as CSA options in southern Africa such as conservation agriculture, agroforestry, crop diversification and climate information services (Zougmoré et al., 2018). However, the rate of adoption of CSA practices and technologies remains low despite the associated benefits (Khatri-Chhetri et al., 2017b; Tiamiyu et al., 2017).

The detrimental impacts of climate variability and change on smallholder farming systems can no longer be ignored or denied (Schulze, 2016). It is therefore imperative for farmers to embrace appropriate adaptation strategies to enhance resilience (Mathews et al., 2018). Smallholder farmers are mostly adversely impacted by the occurrence of climate change and may require support from the local / central government or non-governmental organizations. In order to recommend appropriate forms of support, it is important to assess the status of CSA implementation in the given communities. The next section presents the materials and methods used in this study. 


\section{METHODS}

\section{Study Area Description}

The study focused on the City of Tshwane Metropolitan Municipality which lies on the northern part of Gauteng province of South Africa. Gauteng province is the smallest of the nine provinces of South Africa in terms of geographic extent (Figures 2, 3). It is situated in the north-eastern interior of South Africa, occupying $18,176 \mathrm{~km}^{2}$ or just $1.5 \%$ of the countries' land (Statistics South Africa, 2020). The province is made up three metropolitan municipalities, namely, Ekurhuleni, Johannesburg and Tshwane. Gauteng is regarded as the largest urban economy in Africa (Wray and Cheruiyot, 2015) and includes mining and industrial centers as well as pockets of agricultural hubs. Gauteng province is the financial capital of South Africa and the country's economic hub, contributing about $34 \%$ of the country's GDP (Statistics South Africa, 2019). It is highly urbanized and houses approximately 15.5 million people or $26 \%$ of the country's total population (Statistics South Africa, 2020).

The Gauteng province has about 830,000 hectares of agricultural land, of which, just over half is considered potentially arable and 390,000 ha is suitable for grazing. The province is conveniently positioned for agricultural production, with good infrastructure and access to markets (Gauteng Department of Agriculture Rural Development, 2017).

The agricultural zones in Gauteng province have $\sim 242,594$ agricultural households of which 40,700 rear livestock, 160,700 grow crops and 16,800 practice mixed farming, and only 1,700 (or $<1 \%$ ) are commercial units (Gauteng Department of Agriculture Rural Development, 2017). The sector contributes 0.5\% to GDP and $0.5 \%$ to employment quotient in Gauteng province.

\section{Research Design}

This study adopted a case study design and makes an indepth study of CSA adoption and implementation in selected areas of the City of Tshwane Metropolitan Municipality. The study adopted a cross-sectional (once-off) approach to collect data and a descriptive approach to answer the questions of what, where, when, who and how, with regard to climate smart farming in the study area (University of Southern California Libraries, 2016). Aspects of both quantitative and qualitative procedures were used; thus the study employed the mixed methods approach (Akhtar, 2016). The research strategy used the qualitative approach to decipher social phenomena from the participant's perspectives, and collected quantitative data relating to the existing agricultural practices by the farmers (Tiamiyu et al., 2017). The study made use of primary data from surveys and field observation as well as secondary information from published sources and unpublished information availed during interviews with key informants.

\section{Data Collection Instruments and Methods}

Data collection instruments used in this study consisted of a semi-structured questionnaire, semi-structured key informant interviews, field observations and informal discussions with participants. The semi-structured questionnaire was targeted at smallholder crop farmers as respondents. Face to face engagements were held with thirty-six farmers at their respective farms. Interviews were held with local government officials (in the City of Tshwane Metropolitan Municipality) who were working with the farmers in the four selected locations of Rooiwal, Soshanguve, Mamelodi, and Cullinan. Field observations were conducted to gather supplementary information and to confirm data collected from questionnaires and interviews. Informal discussions were held with participants where appropriate (during field observations), to get clarity or in-depth information on the phenomena being observed.

\section{Sampling Procedure}

Purposive sampling was used to select the City of Tshwane Metropolitan Municipality out of the three metropolitan municipalities of Gauteng province. The municipality was selected based on the study purpose and with the expectation that the regions in the municipality presented diverse agricultural activities that would provide unique and rich information relating to ongoing CSA practices. Participants for the key informant interviews were also selected purposively based on their knowledge and experience as extension service providers in the area (Suen et al., 2014). The City of Tshwane Metropolitan Municipality constitutes seven regions, two of which were selected for the study. Simple random sampling was used to select two regions and then to select four locations within the regions selected for study. Cullinan and Rooiwal (situated in Region 5) and, Mamelodi and Soshanguve (situated in Region 6) were the locations selected (Figure 2).

The target population composed of smallholder crop farmers operating and residing in the study locations. In order to identify the thirty-six crop farmers who participated in the study, snowball sampling was employed. The sample size was decided on after the data collected became constant and repetitive, when it was realized that a bigger sample would not generate new information or increase the precision of the estimator any further (Saunders et al., 2018; Hennink and Kaiser, 2020). It was deemed unnecessary to continue collecting data after the saturation level had been reached.

Quantitative data on tillage system, crop system, soil fertility management, and irrigation types were analyzed by means of descriptive statistics (frequencies and percentages). Qualitative data generated through observations, semi-structured interviews and open-ended questionnaire items were categorized and subjected to content analysis and categorized into themes that relate to the variables assessed by the close-ended questionnaire items to enable, where appropriate, triangulating the data from the different sources.

\section{STUDY FINDINGS}

\section{Agricultural Practices Identified in the Study Area}

Information on the practices conducted by the farmers was collected with the objective of assessing the extent to which these agricultural practices were climate smart. The agricultural practices identified in this study can be categorized into four systems: tillage, cropping, soil fertility management and 


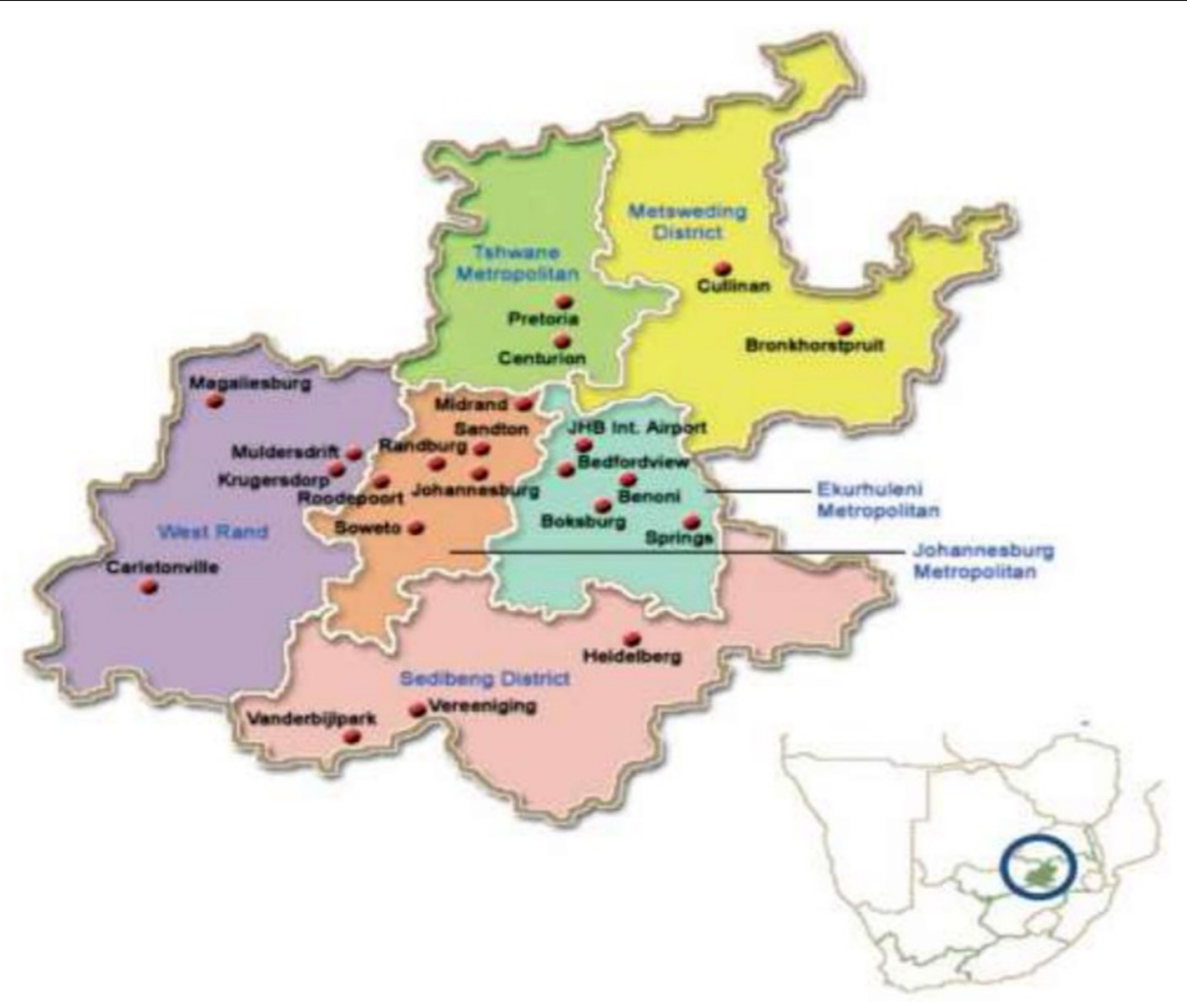

FIGURE 3 | Gauteng City Regions (Gauteng Department of Agriculture Rural Development, 2017).

TABLE 1 | Farming systems and practices identified in City of Tshwane Metropolitan Municipality.

\begin{tabular}{ll}
\hline System & Practices Involved \\
\hline Tillage practices & - Conventional; \\
& - Tractor plowing; \\
& - Basin planting; \\
& - Hand hoe digging \\
& - Crop rotation; \\
Cropping systems & - Sole cropping; \\
& - Intercropping; \\
& - Mulching; \\
& - Inorganic fertilizer \\
Soil fertility management & - Organic fertilizer; \\
& - Leaf litter; \\
& - Animal manure; \\
& - No fertilizer \\
Irrigation methods & - Manual irrigation; \\
& - Drip irrigation; \\
& - Surface (flood) irrigation; \\
& - Sprinklers
\end{tabular}

Compiled through questionnaire, interviews, and field observations.

irrigation systems. This categorization was adopted from a related study conducted by Makuvaro (2014) in smallholder farming communities in Zimbabwe. Table 1 identifies the farming systems and the associated practices.
Figure 4 displays the numbers of farmers that practiced each of the various farming systems. The most commonly utilized tillage system was conventional tillage, reported by 15 respondents. Closely next to this was the use of tractors and hand digging utilized by 10 and 7 respondents, respectively. The least utilized approach was the use of plant basins. None of the respondents applied zero tillage in their farms.

There seemed to be no overwhelmingly popular cropping system. The largest proportion of respondents (44\%) practiced crop rotation. The second most popular cropping system in terms of respondents implementing it was intercropping, implemented by $28 \%$ of the respondents, followed by sole or mono cropping and mulching, each implemented by only $11 \%$ of the respondents.

Regarding soil management, the use of inorganic fertilizer was the most utilized approach with close to half of the respondents (47\%) indicating constant use. The second most popular soil fertility management was the use of animal manure, indicated by $28 \%$ of the respondents. The next was organic fertilizer which was utilized by $17 \%$ of the respondents. One respondent indicated the use of leaf litter while two did not apply any fertilizer.

With respect to irrigation systems, drip and sprinkler irrigation were the two most commonly used include with 44 and $33 \%$ of the respondents, respectively. About $14 \%$ of the respondents used manual irrigation (pouring water using buckets) while $6 \%$ used the surface (flood) method. Observations during the study confirmed some of the irrigation methods that 


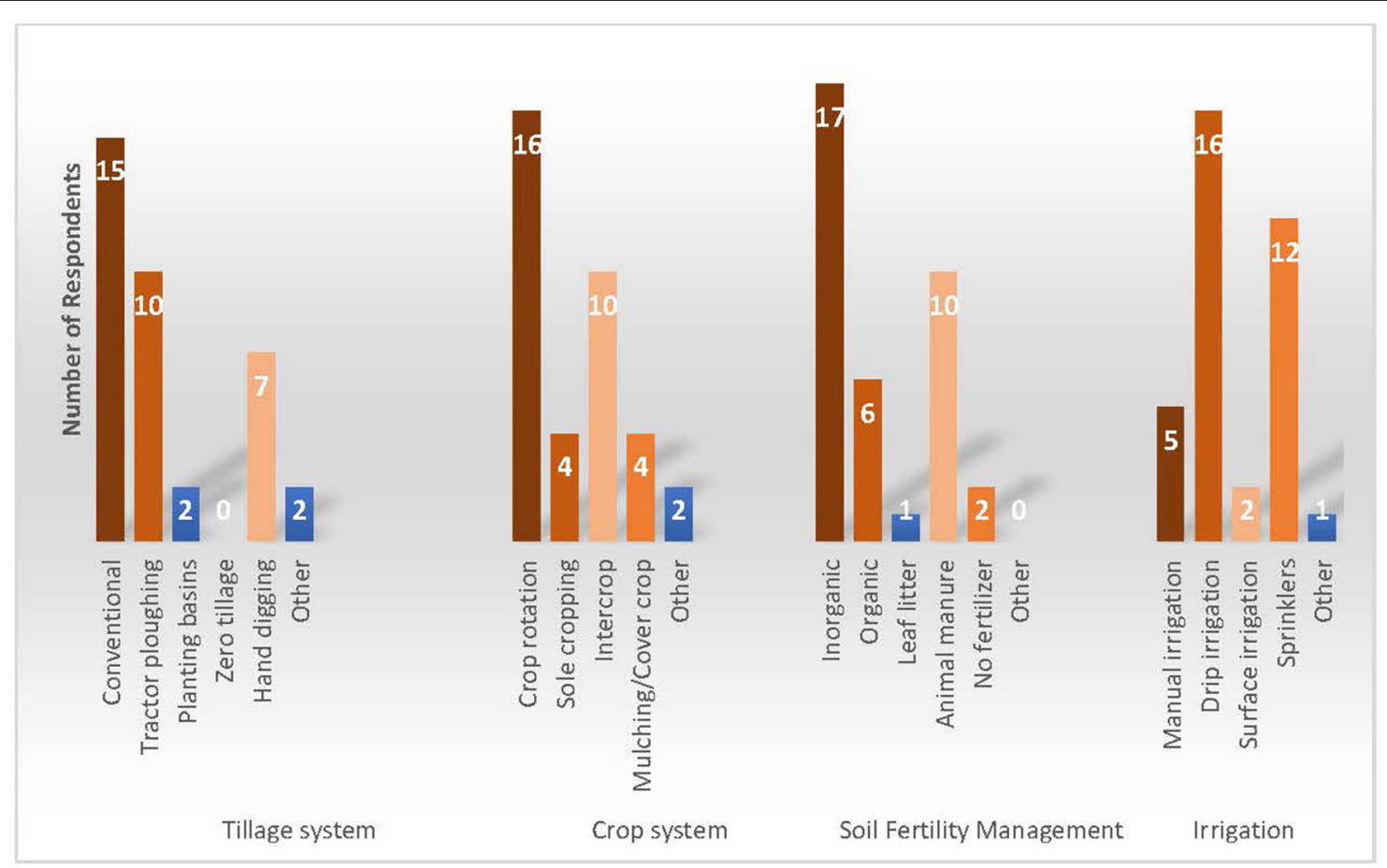

FIGURE 4 | Existing agricultural practices by smallholder farmers in Rooiwal, Soshanguve, Mamelodi, and Cullinan areas who participated in this research. $N=36$. Multiple responses were allowed.

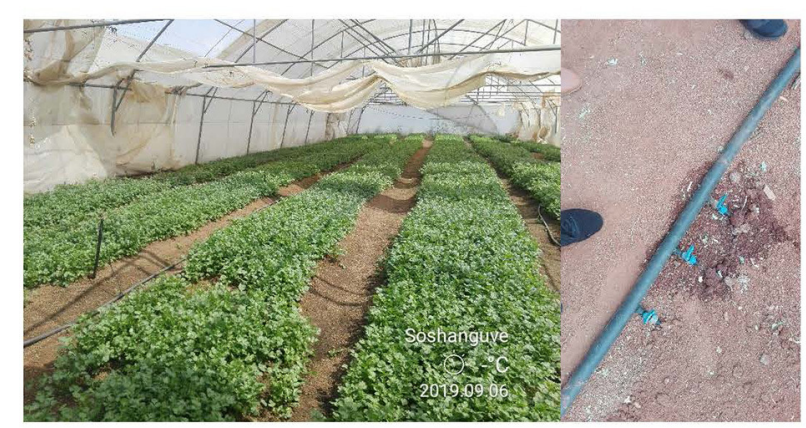

FIGURE 5 | Drip irrigation in a greenhouse in Soshanguve area (Source: survey results - field observations).

were being used in the area. Figure 5 presents a picture of drip irrigation observed during this study.

\section{Respondents' Years of Farming Experience}

The experience of a farmer is known to influence the decision and choices the farmer makes as well as his/her planning for future mitigation strategies (Elum et al., 2017). To be able to make an informed assessment of the farmers' perceptions and practices, this study investigated the participants' years of farming experience. Table 2 shows the number of years the farmers participating in this study have been practicing. A greater proportion $(47 \%)$ of the farmers has been practicing for $11-15$
TABLE 2 | Respondents' number of years of farming experience.

Years of farming experience

Number of respondents

$0-5$

$6-10$

$11-15$

16-20

Over 20

3

12

17

4

0

years and $33 \%$ has been farming for 6-10 years. About $8 \%$ has been practicing for 5 years or less. It was seen that generally farmers who had been practicing for a longer time were more traditional (in terms of methods used) and highly conventional as compared to those new to the field. Such respondents indicated that their indigenous knowledge and skills about farming and adaptation strategies were acquired through generational transfer from their predecessors.

\section{Respondents' Perceptions and Knowledge of Climate Variability and Change Issues}

The study explored the farmers' perceptions and knowledge about climate variability and change, the impacts and ways in which the farmers have adapted. The respondents were also questioned about their knowledge of CSA and whether they implemented any CSA strategies. It can be noted that the concept of CSA was explained in vernacular language to ensure the 
respondents had the same understanding of what practices were implied. The farmers were also asked for their opinions on what they perceived as the most appropriate way forward for the adoption of CSA practices. Figure 6 presents the findings.

The results indicate that all farmers were aware of the concept of climate change. In general, the farmers expressed that over the years, there has been much less rainfall and higher temperatures, which affect their farming activities. In addition, the farmers showed a general awareness that there has been a change in the starting and ending times of seasons, causing difficulties in planning for cultivation.

Figure 6 shows that most respondents (58\%) indicated having experienced the effect of all the climate change indicators or variables on crop health, production and yield. The farmers expressed awareness that temperatures and amount of rainfall received directly affects the soil moisture which determines crop productivity. The study revealed that decision on planting dates was dependent on the available soil moisture as well as availability of seed and draft power.

The findings show that most respondents (61\%), perceived awareness campaigns and training regarding CSA practices as the most critical intervention measures to increase adoption of CSA. Above $50 \%$ of the farmers had no knowledge of CSA practices. This finding explains why most respondents perceived more awareness campaigns and training on CSA practices as an intervention that could increase adoption of CSA practices among smallholder farmers.

A relatively smaller proportion of respondents (22\%) opined that access to credit facilities is important to enhance the capacity of farmers to procure the necessary inputs for climate smart farming. Policy changes to create an enabling environment, training of extension staff and provision of supportive programmes did not seem to be critical measures in this regard. With regard to credit facilities it should be noted however that given the high interest rates charged on loans / credits by banks in South Africa, access to credit facilities per se may not be a panacea for the smallholder farmers as they may struggle to pay back the principal amount together with the interest. The interest rates charged by the banks is in lieu of the costs incurred by the banks as they raise the funds at commercial markets (Land Agricultural Development Bank of South Africa, 2021). The lending institutions require collateral security and do make assessment and give loans only to qualifying candidates (Land Agricultural Development Bank of South Africa, 2021). The study revealed that many smallholder farmers fall out and fail to qualify in this regard. Perhaps, the farmers should get access to soft loans with very minimal interest rates and with flexible terms of repayment, including right-off in the event of poor production due to natural challenges such as prolonged drought.

\section{DISCUSSION}

\section{Tillage Practices and Cropping Systems}

This study revealed that conventional tillage practices (using tractors for cultivation or using hand hoes in cases of inadequate financial resources) were predominantly practiced by the periurban farmers under focus. This is despite the known detrimental effects of these systems on soil quality over time (Makuvaro, 2014). Conventional tillage systems are known to promote soil degradation and are not regarded climate smart.

The study also showed that the use of plant basins was not popular in the area. Basin planting is considered a climate smart practice due to its soil erosion mitigation properties and effectiveness and efficiency in harnessing water resources for the crops (Kaczan et al., 2013). These findings indicate that regarding cultivation and soil preparation, farmers had to a greater extent maintained the conventional practices which are not typically climate smart (with respect to the pillars of productivity, adaptation, and mitigation).

Crop rotation appeared to be common knowledge and practice among the farmers and its positive impacts on soil quality was widely appreciated among the farmers. Despite its benefits, the practice was not maximally implemented in the study area. The study revealed that the types of crops and hectarage cultivated was determined by the demand from consumers. This observation is consistent with the findings by Mudhara (1995) in the Chivi communal areas of Zimbabwe that the farmers conducted crop rotations on only $40 \%$ of maize fields with other crops such as sunflower, pearl millet and groundnuts due to demand factors.

The second most practiced cropping system in the study area was intercropping. According to Muimba-Kankolongo (2018), intercropping involves mixing a number of subsidiary crops on one field often with one base crop to accord higher yields per unit area. This practice maximizes the use of natural resources such as soil moisture, radiation from the sun, and nutrients due to the various crop shapes, root structures, and physiological components of the crops. It is beneficial for the conservation of good soil quality. Sole or mono cropping, defined as a practice whereby a field is used for cultivation of a single crop type (Muimba-Kankolongo, 2018) was one of the least used practices, with 4 respondents indicating use. This reflects that monocropping is not typical of smallholder farming systems except in special cases. An example in this study was a farmer who, due to lack of water resources, cultivated only sunflower plant because it is less intensive with regard to water use and can tolerate short drought periods (Ahmad et al., 2014).

\section{Soil and Water Management Practices}

The use of inorganic fertilizer was the highest utilized soil management practice with close to half the respondents indicating constant use. Many farmers referred to 2:3:2 or 2:3:4 fertilizer, depending on requirements of the soil and crops. The first ratio unit refers to the proportion of nitrogen $(\mathrm{N})$, followed by phosphorus $(\mathrm{P})$ and potassium $(\mathrm{K})$. Applying this type of fertilizer on the soil has negative impacts which include emission of GHG's, disruption of soil as development of new aggregates is impeded, and groundwater pollution through the development and leaching of nitrates via mineralisation of soil micro-organisms that release ammonia (Faurès et al., 2013). The study gathered that high usage of inorganic fertilizer was because of financial constraints of smallholder farmers to purchase environmentally friendly soil management technologies. Inorganic fertilizer was perceived to be cheaper and 


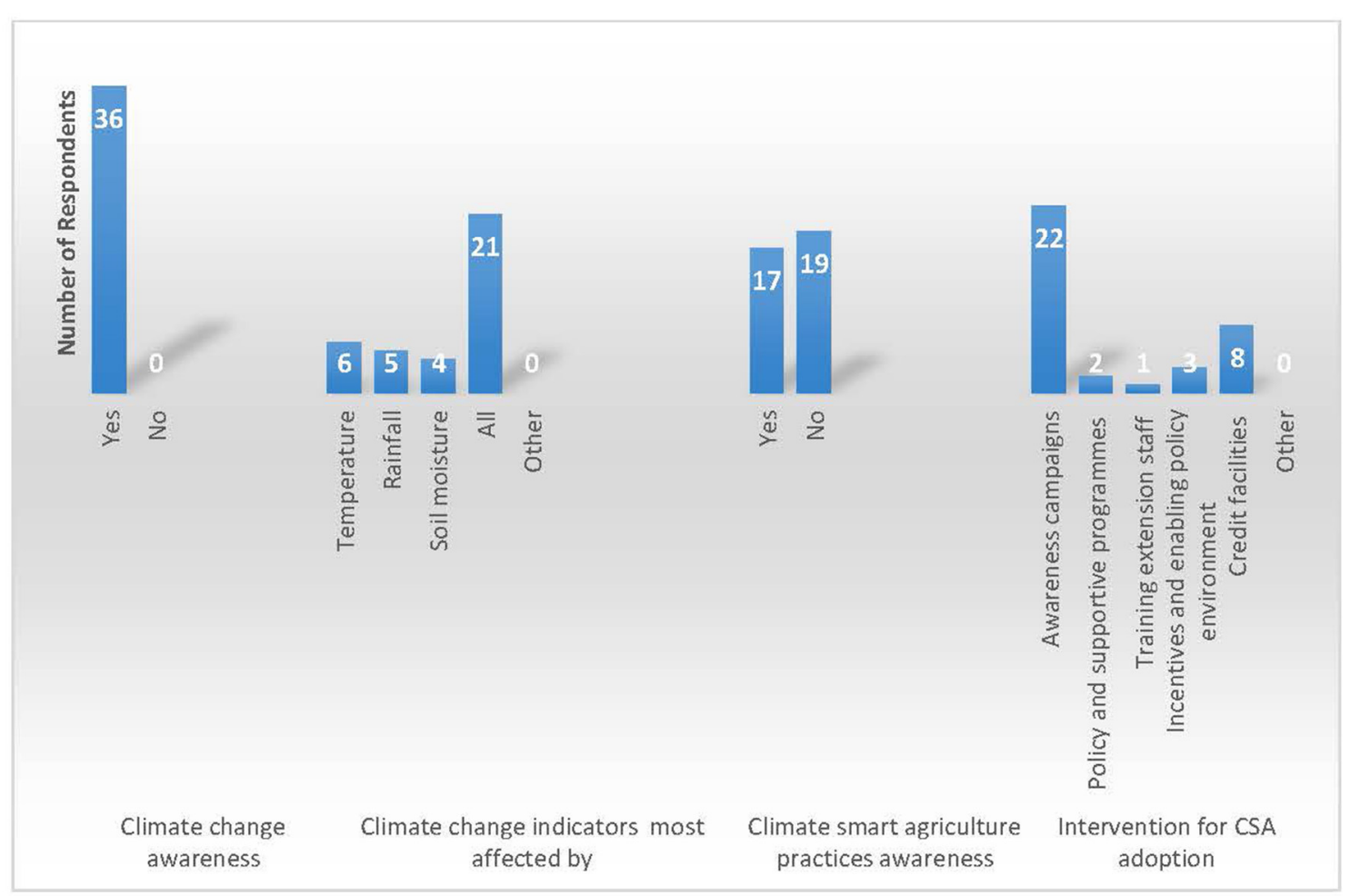

FIGURE 6 | Awareness of climate variability/change and CSA, and perceived interventions.

more effective in terms of yields. According to Hazeltine and Bull (2003), manure and compost are low-strength fertilizers, where $100 \mathrm{~kg}$ chemical fertilizer composed of 10-5-10 contains about the same amount of manure N-P-K of $2,000 \mathrm{~kg}$ on an average farm.

Animal manure was second in use by the participants in this study. Some farmers used chicken manure from the poultry they were rearing. Some farmers could acquire manure from neighboring farms that were rearing poultry or livestock. In such cases, this implied easier access to relatively cheaper animal manure. Only 6 respondents indicated using humus (organic fertilizer) due to the high costs and expenses of this fertilizer which oftentimes become a liability.

The two commonly used irrigation systems include drip irrigation and sprinklers by 44 and $33 \%$ of the respondents, respectively, followed by manual irrigation (14\%) which included the use of hose pipes.

\section{Awareness of Climate Change and Adaptation Mechanisms Adopted}

There was an overwhelming awareness among the respondents, of climate change and its impacts on crop productivity and yields. The findings in this study concur with the findings by Dube et al. (2021) among peri-urban farmers in Bulawayo, Zimbabwe. The present study confirmed that the farmers have, over time, adapted various ways of addressing the impacts of climate change. Some farmers in this study, mainly those with over 10 years of experience, expressed that the use of indigenous knowledge has enabled them to withstand the challenges of climate change. Strategies used included growing nitrogen-fixing crops (legumes) in rotation and the use of higher soil organic matter which result in reduced use of inorganic fertilizers and reduced demand for water. Other farmers resorted to tilling the soil just before the rains come to enable the soil to hold onto the water for longer periods of time. These results compare well with the findings by Rakgase and Norris (2015) which showed that the perception of older farmers to climate change and its impacts such as drought is critical as they have been highly exposed and have experienced the changing conditions over the years, and have observed the severity of the impacts. Further research is required to verify the conception by the farmers of tilling the land just before the rains since this conception is inconsistent with research findings showing more runoff on occasional strategic tillage plots compared to no tillage treatments (Dang et al., 2018).

\section{Climate Smartness of Agricultural Practices in the Study Locations}

Manda et al. (2019) point out that the climate smartness of practices depends on their ability to enhance food security, mitigate against climate change and assist in reducing GHG emissions. However, there is no specific guideline or criteria on what should be included, as CSA includes various practices or technologies making it a challenge to prioritize CSA objectives. Further, there is a lack of a workable method to assess climate 
smartness of practices as there is limited amount of information available to assess the impacts. According to Bell et al. (2018) the impacts of CSA are the culmination of three outcomes which are the pillars of CSA which include productivity (measured through yield or economics), resilience (measured by means of any factor that has the capacity to buffer a system) or mitigation.

Lima (2014) notes that there are examples of traditional and research-based agricultural practices in every country that can be considered climate smart, however, such are not mainstreamed and do not get adequate support. These include agroecological practices such as agroforestry, mulching, mixed farming, intercropping and growing of drought-tolerant and/or high-yielding crop varieties.

In this study, climate smartness was determined by the potential for the practices to achieve the pillars of CSA, that is, reducing GHG emissions, increasing food security and increasing the resilience of the farming systems against climate variability and change. In a water scarce country like South Africa, and the Gauteng province in particular, practices such as mulching, cover-cropping and crop rotation practiced by the farmers in the four study locations, would be considered climate smart. This is because they act as water conserving practices; improve soil quality, structure and fertility and reduce runoff. These attributes contribute greatly to food security and adaptation to climate variability and change leading to the achievement of the adaptation and food security goals. Manda et al. (2019) arrived at a similar conclusion in a study in the Lushoto community in Tanzania. According to Huyer and Nyasimi (2017), in terms of the adaptation pillar, these practices promote increased water retention which assists in the reduction of crop losses. With regard to mitigation, the practices have the capacity to improve carbon storage in the soil whilst retaining soil moisture. On one hand, this leads to increased productivity enabled by higher soil nutrients while on the other hand, promotes reduction in soil erosion.

This study found crop rotation to be the most frequently used practice among the farmers under focus. The practice of crop rotation is used to address agroecological issues relating to declining soil quality. The practice involves growing plants in sequence on the same land, fostering carbon sequestration. The practice has the potential to reduce Methane $\left(\mathrm{CH}_{4}\right)$ and other GHGs emissions, increase crop yields and productivity, reduce soil erosion, increase nutrient cycling and reduce pests and diseases (Singh and Singh, 2017; Partey et al., 2018).

The use of crop varieties by farmers is considered climate smart because it has the capacity to control pests, increase yields and increase drought tolerance. Since the practice accords improved resilience it helps to achieve the adaptation pillar. It also applies to the production pillar, considering the potential to enable high sustainable yields (Huyer and Nyasimi, 2017). In line with this observation, Singh and Singh (2017) confirmed that mixed cropping reduces pests and diseases as well as the risk of crop failure whilst increasing food supply by an estimated $15-20 \%$.

Traditional organic composting including animal and chicken manure enhances the soil organic matter and improves carbon sequestration (Singh and Singh, 2017). This addresses the mitigation and resilience pillars of CSA. A study by Subedi et al. (2019) assessed CSA practices that increase crop yield and compared various soil fertility practices found that in Nepal the application of jholmal (which is a mixture of animal manure and water) increased yields of rice by $15.5 \%$ and reflected similar results in four other tested sites, as compared to the use of inorganic fertilizers. The most frequently used soil fertility management practice in the current study locations was inorganic (chemical) fertilizer followed by animal manure. The proportions of farmers using organic fertilizers was relatively low (28\%), which is concerning.

Irrigation practices were generally minimal in the area under focus. Manual irrigation methods were less popular in the area. The study gathered through key informant interviews that this was because these irrigation methods were labor intensive and not water efficient. The use of the drip system and sprinklers were the most used. The farmers who used these indicated that the practices were convenient and conserve water thus, appropriate in water scarce areas. Key informant interviews revealed that drip irrigation utilizes a lot less water due to its targeted crop irrigating model and was perceived to be economically viable for the low-income farmers under focus. Drip irrigation is an advanced irrigation method characterized by frequent and precise application of water in small amounts through a system of plastic pipes onto the root zone of crops in localized areas (Patle et al., 2020). It assists the conservation of water yielding better returns for farmers' investments (Balana et al., 2017). The irrigation efficiency is up to $90 \%$-depending on the crop and soil types, root depths and weather conditions. Due to these features, drip irrigation is climate smart due to its capacity to create resilience and to mitigate against impacts of climate variability or change. It also has benefits such as increasing crop yields and reducing diseases and bleaching since the application is not on foliage. The use of drip irrigation thus has the potential to enhance food security and improve the farmer's livelihoods (Balana et al., 2017).

\section{Scaling Up Uptake of CSA Technologies and Practices}

The term scaling up refers to a variety of processes which are defined in different ways (Makate, 2019). In this study, the term implies horizontal scaling up (also referred to as scaling out) whereby the adoption of CSA spreads across the geographical area with more farmers adopting the technologies. The term also implies vertical scaling up whereby a technology that has been used by one farmer becomes adopted by a group of farmers or association of farmer groups (Makate, 2019). The farmers in this study were employing various adaptation and mitigation strategies in response to climate variability and change even though the level of awareness of the concept of CSA was low. These results compare well with the findings of Knegtel and Naidoo (2014) that some farmers in the city of Durban in South Africa were implementing climate-smart agricultural techniques but they were not aware that such techniques were climate-smart. It is possible that due to limited access to scientific information smallholder farmers may not have 
knowledge of technical terms such as CSA yet they may possess knowledge of some CSA practices acquired and accumulated over years of experience, often transferred from one generation to another (Horamo et al., 2021). The farmers in the study area were implementing adaptation mechanisms acquired from indigenous systems as well as scientific knowledge acquired through agricultural extension services. However, much more can be done to scale up the uptake of CSA in the Gauteng region in terms of geographical spread of technology adoption as well as more intensive implementation of the adopted technologies. Peri-urban areas are highly vulnerable to climate-related disasters partly due to dwindling traditional informal institutions and the associated forms of collective action and interdependence in these communities (Revi et al., 2014). Therefore, local authorities should consider reviving and empowering local traditional institutions that can help to promote technology adoption in these smallholder farming communities.

\section{CONCLUSION}

This study focused on smallholder crop farmers in the periurban areas of Tshwane Metropolitan Municipality in Gauteng Province. The findings revealed overwhelming awareness of the impacts of climate variability or change on production and food security. To some extent, the farmers were employing various adaptation and mitigation strategies against these impacts even though the level of awareness of the concept of CSA was low. The study revealed that the non-climate smart conventional tillage practices were predominantly practiced by the peri-urban farmers under focus. Some CSA practices acquired through indigenous knowledge systems or scientific knowledge were implemented in the study area but to a limited scale or intensity. Much more could be done by the local authorities, extension service providers and the farmers to jointly scale up the uptake of CSA in the Gauteng region. The study recommends inter-connected interventions involving traditional institutions, extension service providers and the media to support the farmers. The interventions may include creating capacity development which may involve institutional and financial support for farmers to make the transition to CSA. The study also recommends investments in technology developments and the adoption of

\section{REFERENCES}

Ahmad, R., Waraich, E. A., Ashraf, M. Y., Ahmad, S., and Aziz, T. (2014). Does nitrogen fertilization enhance drought tolerance in sunflower? A review. J. Plant Nutr. 37, 942-963. doi: 10.1080/01904167.2013.868480

Akhtar, M. I. (2016). Research design. Res. Soc. Sci. Interdisci. Perspect. 68-84. doi: $10.2139 /$ ssrn. 2862445

Akinnagbe, O. M., and Irohibe, I. J. (2014). Agricultural adaptation strategies to climate change impacts in Africa: a review. Bangladesh J. Agri. Res. 39, 407-418.

Anaafo, D., and Akolgo, G. A. (2018). The role of urban agriculture in climate change mitigation and adaptation in Ghanaian cities. J. Energy Nat. Resourc. Manage. 1, 23-28. doi: 10.26796/jenrm.v1i2.132

Andrieu, N., Sogoba, B., Zougmore, R., Howland, F., Samake, O., Bonilla-Findji, O., et al. (2017). Prioritizing investments for climate-smart agriculture: Lessons learned from Mali. Agric. Syst. 154, 13-24. doi: 10.1016/j.agsy.2017.02.008 inter-sectoral approaches to achieve CSA objectives (Sulaiman et al., 2018). Capacity building by stakeholders in the form of training workshops, CSA information dissemination, one-onone extension engagements and campaigns to raise the awareness of CSA technologies appropriate to the unique conditions of each farmer are recommended. Various stakeholders which can be involved include government extension staff, farmer associations, the private sector, the public sector and researchers. The study further recommends policy development to support the upscaling of CSA technology adoption in peri-urban areas. This is not to call for the development of a new CSA policy as such but the adjustment of existing policies and improvement of coordination of policies to ensure policy frameworks that are supportive of CSA (Williams et al., 2015).

\section{DATA AVAILABILITY STATEMENT}

The datasets presented in this article are not readily available because may require additional ethics clearance to share original data with a third party. Requests to access the datasets should be directed to chitam1@unisa.ac.za.

\section{ETHICS STATEMENT}

The studies involving human participants were reviewed and approved by UNISA-CAES Health Research Ethics Committee. The patients/participants provided their written informed consent to participate in this study.

\section{AUTHOR CONTRIBUTIONS}

MC: conceptualization, project plan, project supervision data analysis, manuscript writing, and manuscript revision. NZPN: conceptualization, project plan, data collection, data analysis, and draft report writing. Both authors contributed to the article and approved the submitted version.

\section{ACKNOWLEDGMENTS}

We appreciate the valuable support provided by the Environment and Agriculture Management Department of the City of Tshwane and by the University of South Africa. 
City of Tshwane (2015). City of Tshwane Climate Risk and Vulnerability Assessment. Pretoria: City of Tshwane.

Cofie, O. O., Van Veenhuizen, R., and Drechsel, P. (2003). Contribution of Urban and Peri-Urban Agriculture to Food Security in Sub-Saharan Africa. Kyoto: WWF.

Dang, Y. P., Balzer, A., Crawford, M., Rincon-Florez, V., Liu, H., Melland, A. R., et al. (2018). Strategic tillage in conservation agricultural systems of northeastern Australia: why, where, when and how? Environ. Sci. Pollut. Res. 25, 1000-1015. doi: 10.1007/s11356-017-8937-1

Department of Environmental Affairs (2016). "Climate change adaptation perspectives on food security," in Long-Term Adaptation Scenarios Flagship Research Programme, eds S. M. Munzhedzi, V. P. Khavhagali, G. M. Midgley, P. de Abreu, S. Scorgie, M. Braun, Z. Abdul, F. Ferdi Meyer, J. Greyling, G. van der Burgh, H. Vermeulen, M. Muhl, L. Trapnell, J. Cullis (Pretoria: DEA).

Dube, T., Sibanda, S., and Chiwara, P. (2021). Adapting peri-urban agriculture to climate change in Bulawayo, Zimbabwe: a qualitative assessment. Cogent Soc. Sci. 7:194448. doi: 10.1080/23311886.2021.1944486

Elum, Z. A., Modise, D. M., and Marr, A. (2017). Farmer's perception of climate change and responsive strategies in three selected provinces of South Africa. Clim. Risk Manage. 16, 246-257. doi: 10.1016/j.crm.2016.11.001

Faurès, J. M., Bartley, D., Bazza, M., Burke, J., Hoogeveen, J., Soto, D., et al. (2013). Climate Smart Agriculture Sourcebook. Rome: FAO.

Finger, R., and Schmid, S. (2007). Modeling agricultural production risk and the adaptation to climate change (No. 686-2016-47118). Available online at: https:// mpra.ub.uni-muenchen.de/3943/1/MPRA_paper_3943.pdf

Food and Agricultural Organisation (2010). Climate-Smartagriculture: Policies, Practices and Financing for Food Security, Adaptation and Mitigation. Rome: FAO.

Gauteng Department of Agriculture and Rural Development (2017). Over-Arching Climate Change Response Strategy 2017 Adaptation Strategy for Agriculture in Gauteng. Johannesburg: GDARD.

Government of South Africa (2021). Municipalities of South Africa. Available online at: https://municipalities.co.za/map/3/city-of-tshwane-metropolitanmunicipality (accesesed December 7, 2021).

Hazeltine, B., and Bull, C. (Eds.). (2003). Field Guide to Appropriate Technology. San Diego, CA: Elsevier.

Hennink, M. M., and Kaiser, B. N. (2020). Saturation in Qualitative Research. London: SAGE Publications Limited.

Horamo, Y., Chitakira, M., and Yessoufou, K. (2021). Farmers' knowledge is the basis for local level agro-forestry management: the Case of Lemo Woreda in Hadiya Zone, Ethiopia. Front. Sust. Food Syst. 5:739061. doi: $10.3389 /$ fsufs.2021.739061

Huyer, S., and Nyasimi, M. (2017). Climate-Smart Agriculture Manual for Agriculture Education in Zimbabwe. Copenhagen: Climate Technology Centre and Network.

Iizumi, T., and Ramankutty, N. (2015). How do weather and climate influence cropping area and intensity? Glob. Food Sec. 4, 46-50. doi: 10.1016/j.gfs.2014.11.003

Intergovernmental Panel on Climate Change (2007). Intergovernmental Panel on Climate Change Fourth Assessment Report. Cambridge: Cambridge University Press.

IPCC (2018): “Annex I: glossary [Matthews, J.B.R. (ed.)],” in Global Warming of $1.5^{\circ} \mathrm{C}$. An IPCC Special Report on the Impacts of Global Warming of $1.5^{\circ} \mathrm{C}$ Above Pre-industrial Levels and Related Global Greenhouse Gas Emission Pathways, in the Context of Strengthening the Global Response to the Threat of Climate Change, Sustainable Development, and Efforts to Eradicate Poverty, eds V. Masson-Delmotte, P. Zhai, H.-O. Pörtner, D. Roberts, J. Skea, P.R. Shukla, A. Pirani, W. Moufouma-Okia, C. Péan, R. Pidcock, S. Connors, J.B.R. Matthews, Y. Chen, X. Zhou, M.I. Gomis, E. Lonnoy, T. Maycock, M. Tignor, and T. Waterfield. Available online at: https://www.ipcc.ch/sr15/chapter/glossary/ (accessed November 20, 2021).

Kaczan, D., Arslan, A., and Lipper, L. (2013). Climate-Smart Agriculture? A Review of Current Practice of Agroforestry and Conservation Agriculture in Malawi and Zambia. ESA Working Paper No. 13-07. Rome: Food and Agriculture Organization.

Khatri-Chhetri, A., Aggarwal, P. K., Joshi, P. K., and Vyas, S. (2017a). Farmers' prioritization of climate-smart agriculture (CSA) technologies. Agric. Syst. 151, 184-191. doi: 10.1016/j.agsy.2016.10.005
Khatri-Chhetri, A., Poudel, B., Shirsath, P. B., and Chaudhary, P. (2017b). Assessment of Climate-Smart Agriculture (CSA) Options in Nepal. CGIAR Research Program on Climate Change, Agriculture and Food Security (CCAFS). New Delhi: CGIAR.

Knegtel, J., and Naidoo, S. (2014). Climate-smart urban agriculture in eThekwini. Quest 10, 3-5. Available online at: https://hdl.handle.net/10520/EJC164367

Land and Agricultural Development Bank of South Africa (2021). Frequently Asked Questions. Available online at: https://landbank.co.za/Pages/FAQs. aspxhttps://landbank.co.za/Pages/FAQs.aspx (accessed May 3, 2021).

Lima, M. G. B. (2014). Policies and Practices for Climate-Smart Agriculture in Sub-Saharan Africa: A Comparative Assessment of Challenges and Opportunities Across 15 Countries. Africa Portal Roundup Newsletter.

Makate, C. (2019). Effective scaling of climate smart agriculture innovations in African smallholder agriculture: A review of approaches, policy and institutional strategy needs. Environ. Sci. Policy 96, 37-51.

Makuvaro, V. (2014). Impact of Climate Change on Smallholder Farming in Zimbabwe, Using a Modelling Approach. Doctoral dissertation. Bloemfontein: University of the Free State.

Manda, L. T., Notenbaert, A. M., and Groot, J. C. (2019). "A participatory approach to assessing the climate-smartness of agricultural interventions: the lushoto case," in The Climate-Smart Agriculture Papers (Cham: Springer), 163-174. doi: 10.1007/978-3-319-92798-5_14

Mathews, J. A., Kruger, L., and Wentink, G. J. (2018). Climate-smart agriculture for sustainable agricultural sectors: The case of Mooifontein. Jàmbá J. Disast. Risk Stud. 10, 1-10. doi: 10.4102/jamba.v10i1.492

Milder, J., Majanen, T., and Scherr, S. (2011). Performance and Potential of Conservation Agriculture for Climate Change Adaptation and Mitigation in SubSaharan Africa: An Assessment of WWF and CARE Projects in Support of the WWF-CARE Alliance's Rural Futures Initiative, Final Report. Washington DC: EcoAgriculture Partners and CARE-WWF Alliance.

Moreau, T. L., Adams, T., Mullinix, K., Fallick, A., and Condon, P. M. (2012). "Chapter 25 recommended practices for climate-smart urban and peri-urban agriculture," in Sustainable Food Planning: Evolving Theory and Practice. Wageningen: Wageningen Academic Publishers. doi: 10.3920/978-90-8686-187-3_25

Mudhara, M. (1995). "Maize production in the face of unreliable rainfall. A case study of Chivi communal area," in Proceedings of the Fourth Eastern and Southern Africa Regional maize Conference. Harare: Maize Research for Stress Environments.

Muimba-Kankolongo, A. (2018). Food Crop Production by Smallholder Farmers in Southern Africa: Challenges and Opportunities for Improvement. London: Academic Press. doi: 10.1016/B978-0-12-814383-4.00013-X

Nagargade, M., Tyagi, V., and Kumar, M. (2017). Climate smart agriculture: an option for changing climatic situation. Plant Engineering (IntechOpen), 143-165. doi: 10.5772/intechopen.69971

Partey, S. T., Zougmoré, R. B., Ouédraogo, M., and Campbell, B. M. (2018). Developing climate-smart agriculture to face climate variability in West Africa: challenges and lessons learnt. J. Clean. Product. 187, 285-295. doi: 10.1016/j.jclepro.2018.03.199

Patle, G. T., Kumar, M., and Khanna, M. (2020). Climate-smart water technologies for sustainable agriculture: a review. J. Water Clim. Change 11,1455-1466. doi: $10.2166 /$ wcc. 2019.257

Pereira, L. (2017). "Climate change impacts on agriculture across Africa," in Oxford Research Encyclopedia of Environmental Science. Oxford: Oxford University Press. doi: 10.1093/acrefore/9780199389414.013.292

Rakgase, M. A., and Norris, D. (2015). Determinants of livestock farmers' perception of future droughts and adoption of mitigating plans. Int. J. Clim. Change Strat. Manage. 7, 191-205. doi: 10.1108/IJCCSM-01-2014-0011

Rao, C. S., Kareemulla, K., Krishnan, P., Murthy, G. R. K., Ramesh, P., Ananthan, P. S., et al. (2019). Agro-ecosystem based sustainability indicators for climate resilient agriculture in India: a conceptual framework. Ecol. Indicat. 105, 621-633. doi: 10.1016/j.ecolind.2018.06.038

Revi, A., Satterthwaite, D. E., Aragón-Durand, F., Corfee-Morlot, J., Kiunsi, R. B. R., Pelling, M., et al. (2014). "Urban areas," in Climate Change 2014: Impacts, Adaptation, and Vulnerability. Part A:Global and Sectoral Aspects. Contribution of Working Group II to the Fifth Assessment Report of the Intergovernmental Panel on Climate Change, eds C. B. Field, V. R. Barros, D. J. Dokken, K. J. Mach, M. D. Mastrandrea, T. E. Bilir, M. Chatterjee, K. L. Ebi, Y. O. Estrada, R. C. 
Genova, B. Girma, E. S. Kissel, A. N. Levy, S. MacCracken, P. R. Mastrandrea, and L. L. White (Cambridge: Cambridge University Press), 535-612.

Saunders, B., Sim, J., Kingstone, T., Baker, S., Waterfield, J., Bartlam, B., et al. (2018). Saturation in qualitative research: exploring its conceptualization and operationalization. Qual. Quant. 52, 1893-1907. doi: $10.1007 / \mathrm{s} 11135-017-0574-8$

Schulze, R. E. (2016). "On observations, climate challenges, the south african agriculture sector and considerations for an adaptation handbook," in Handbook for Farmers, Officials and Other Stakeholders on Adaptation to Climate Change in the Agriculture Sector within South Africa. ed R. E. Schulze. Pretoria: Department of Agriculture, Forestry and Fisheries.

Singh, R., and Singh, G. S. (2017). Traditional agriculture: a climate-smart approach for sustainable food production. Energy Ecol. Environ. 2, 296-316. doi: 10.1007/s40974-017-0074-7

South African Weather Services (2015). Summary of SAWS Research on Historical Climate Trends in South Africa: 1961-2014. CLS-CDAR Report 2014-09. Pretoria: South African Weather Services.

Statistics South Africa (2019). Four Facts About our Provincial Economies. Available online at: http://www.statssa.gov.za/?p=12056 (accessed April 7, 2021).

Statistics South Africa (2020). Mid-Year Population Estimates. Available online at: http://www.statssa.gov.za/?p=13453andgclid= EAIaIQobChMIx7Lc9rDs7wIVDLbtCh0UdQFdEAAYASAAEgKdJPD_ BwE (accessed April 7, 2021).

Subedi, R., Bhatta, L. D., Udas, E., Agrawal, N. K., Joshi, K. D., and Panday, D. (2019). Climate-smart practices for improvement of crop yields in mid-hills of Nepal. Cogent Food Agric. 5:1631026. doi: 10.1080/23311932.2019.1631026

Suen, L. J. W., Huang, H. M., and Lee, H. H. (2014). A comparison of convenience sampling and purposive sampling. Hu Li Za Zhi 61:105. https://www.proquest. com/scholarly-journals/comparison-convenience-sampling-purposive/ docview $/ 1537381331 / \mathrm{se}-2$ ?accountid $=14648$

Sulaiman, R., Chuluunbaatar, D., and Vishnu, S. (2018). Upscaling climate smart agriculture-lessons for extension and advisory services. Occasional Papers on Innovation in Family Farming. Rome: FAO.

Thierfelder, C., Chivenge, P., Mupangwa, W., Rosenstock, T. S., Lamanna, C., and Eyre, J. X. (2017). How climate-smart is conservation agriculture (CA)?-its potential to deliver on adaptation, mitigation and productivity on smallholder farms in southern Africa. Food Secur. 9, 537-560. doi: 10.1007/s12571-017-0665-3

Tiamiyu, S. A., Ugalahi, U. B., Fabunmi, T., Sanusi, R. O., Fapojuwo, E. O., and Shittu, A. M. (2017). "Analysis of farmers' adoption of climate smart agricultural practices in Northern Nigeria," in Proceedings of the 4th International Conference on Agriculture and Forestry (Colombo: The International Institute of Knowledge Management (TIIKM)), 19-26.
UNFCCC (2013). Reporting and Accounting of LULUCF Activities Under the Kyoto Protocol. Bonn: United Nations Framework Convention on Climatic Change (UNFCCC).

University of Southern California Libraries (2016). Organizing Your Social Sciences Research Paper: Types of Research Designs. Available online at: http://libguides. usc.edu/content.php?pid=83009andsid=818072 (accessed November 12, 2021).

Viswanathan, P. K., Kavya, K., and Bahinipati, C. S. (2020). Global patterns of climate-resilient agriculture: a review of studies and imperatives for empirical research in India. Rev. Dev. Change 25, 169-192. doi: $10.1177 / 0972266120966211$

Williams, T. O., Mul, M. L., Cofie, O. O., Kinyangi, J., Zougmoré, R. B., Wamukoya, G., et al. (2015). "Climate smart agriculture in the African context," in Background Paper. Feeding Africa Conference. Available online at: https:// cgspace.cgiar.org/handle/10568/68944 (accessed December 7, 2021).

World Bank., CIAT., and CATIE (2014). Climate-Smart Agriculture in Colombia. CSA Country Profiles for Latin America Series. The World Bank Group, Washington D.C.

Wray, C., and Cheruiyot, K. (2015). Key challenges and potential urban modelling opportunities in South Africa, with specific reference to the Gauteng Cityregion. South Afr. J. Geomat. 4, 14-35. doi: 10.4314/sajg.v4i1.2

Zougmoré, R. B., Partey, S. T., Ouédraogo, M., Torquebiau, E., and Campbell, B. M. (2018). Facing climate variability in sub-Saharan Africa: analysis of climate-smart agriculture opportunities to manage climate-related risks. Cahiers Agric. 27, 1-9. doi: 10.1051/cagri/20 18019

Conflict of Interest: The authors declare that the research was conducted in the absence of any commercial or financial relationships that could be construed as a potential conflict of interest.

Publisher's Note: All claims expressed in this article are solely those of the authors and do not necessarily represent those of their affiliated organizations, or those of the publisher, the editors and the reviewers. Any product that may be evaluated in this article, or claim that may be made by its manufacturer, is not guaranteed or endorsed by the publisher.

Copyright $\odot 2021$ Chitakira and Ngcobo. This is an open-access article distributed under the terms of the Creative Commons Attribution License (CC BY). The use, distribution or reproduction in other forums is permitted, provided the original author(s) and the copyright owner(s) are credited and that the original publication in this journal is cited, in accordance with accepted academic practice. No use, distribution or reproduction is permitted which does not comply with these terms. 